\title{
Visual field loss associated with vigabatrin: pathological correlations
}

J Ravindran, P Blumbergs, J Crompton, G Pietris and H Waddy

J. Neurol. Neurosurg. Psychiatry 2001;70;787-789

doi:10.1136/jnnp.70.6.787

Updated information and services can be found at:

http://jnnp.bmj.com/cgi/content/full/70/6/787

\section{These include:}

References This article cites 12 articles, 7 of which can be accessed free at: http://jnnp.bmj.com/cgi/content/full/70/6/787\#BIBL

5 online articles that cite this article can be accessed at: http://jnnp.bmj.com/cgi/content/full/70/6/787\#otherarticles

Rapid responses You can respond to this article at: http://jnnp.bmj.com/cgi/eletter-submit/70/6/787

Email alerting Receive free email alerts when new articles cite this article - sign up in the box at the service top right corner of the article

Notes

To order reprints of this article go to:

http://journals.bmj.com/cgi/reprintform

To subscribe to Journal of Neurology, Neurosurgery, and Psychiatry go to:

http://journals.bmj.com/subscriptions/ 


\title{
SHORT REPORT
}

\section{Visual field loss associated with vigabatrin: pathological correlations}

\author{
J Ravindran, P Blumbergs, J Crompton, G Pietris, H Waddy
}

\begin{abstract}
Pathological changes are reported in the anterior visual pathways of a 41 year old man with complex partial seizures treated with vigabatrin who developed bilateral visual field constriction. There was peripheral retinal atrophy with loss of ganglion cells and loss of nerve fibres in the optic nerves, chiasm, and tracts. No evidence of intramyelinic oedema was seen. These findings suggest that the primary site of injury lies within the ganglion cells in the retina. The degree of atrophy seen would suggest that the visual field loss is irreversible.

(F Neurol Neurosurg Psychiatry 2001;70:787-789)
\end{abstract}

Keywords: vigabatrin; visual field; retina

Vigabatrin, an analogue of $\gamma$-aminobutyric acid (GABA), irreversibly inhibits GABA transaminase with resultant increased concentrations of GABA in the brain and has proved efficacy in the treatment of partial seizures and infantile spasms. ${ }^{1}$ After the first report of visual field constriction secondary to vigabatrin, this phenomenon has become increasingly well recognised, with a reported incidence varying from $40 \%$ to $52 \% .^{2-4}$ The underlying mechanism is poorly understood. ${ }^{5}$

We report the pathological changes in the anterior visual system of a 41 year old man with complex partial seizures who presented with visual field constriction. He had congenital cyanotic heart disease, with a double outlet single ventricle of the left ventricular type, for which he received supplemental oxygen, warfarin, and frusemide. Idiopathic adrenal failure was diagnosed at the age of 38 years, managed with $15 \mathrm{mg}$ cortisone acetate daily. At the age of 33 years, he presented with complex partial seizures secondary to a streptococcal cerebral abscess in the right parieto-occipital lobe. $\mathrm{He}$ underwent stereotactic drainage and prolonged antibiotic treatment. Brain CT 6 months later confirmed complete resolution of the abscess.

Initial treatment of complex partial seizures comprised 2 g/day clonazepam and 400 $\mathrm{mg}$ /day phenytoin. Phenytoin was substituted with $1400 \mathrm{mg} /$ day sodium valproate 4 years later, which continued to the time of his death. Two and a half years later vigabatrin was started (increasing from $2 \mathrm{~g} /$ day to $6 \mathrm{~g} /$ day over 4 months) and clonazepam was stopped. Vigabatrin was continued at $6 \mathrm{~g} /$ day for 5 months followed by $5 \mathrm{~g}$ /day for 12 months. Over the next 7 months, until the time of death, the dose was maintained at $3 \mathrm{~g} /$ day. He received gabapentin (900 mg/day) for 2 months, 8 months before his death.

Four months before his death, he noted visual difficulties and automated visual field testing (Octopus 1-2-3 Seven-in-One programme) showed constricted visual fields. Two months before his death, he noted an inability to see houses along the street while walking along the footpath. One month before his death, automated visual field testing (Humphrey Field Analyser Program 30-2 and 24-2) showed bilateral concentric constriction of visual fields, especially the nasal fields (fig $1 \mathrm{~A}$, B). The optic discs looked healthy. Vigabatrin was stopped abruptly. Subsequently he had complex partial seizures and cardiopulmonary arrest with electromechanical disassociation and died.

At postmortem the eyes, intraorbital and intracranial optic nerves, and brain were removed for neuropathological examination. Routine histological assessment of the retinas (haematoxylin and eosin stained paraffin sections of formalin fixed tissue) showed severe atrophy of the peripheral retinas (nasal and temporal) and less severe involvement of the maculae. The peripheral retinas showed severe (almost complete) loss of ganglion cells (layer 8 ) and partial loss of nuclei from the inner nuclear layer 6 and outer nuclear layer 4 and atrophy of outer and inner plexiform layers 5 and 7 and nerve fibre layer 9 (fig $2 \mathrm{~A}, \mathrm{~B}$ ). The optic papillae were atrophic and serial step sections of the optic nerves showed severe atrophy (a half to a third normal size) and relative preservation of the macular fibres compared with peripheral retinal fibres (fig $2 \mathrm{C}$ ). The optic chiasm was atrophic with relative preservation of macular fibres posteriorly (little chiasma of Traquair). The optic tracts showed relative preservation of the central macular fibres and loss of medial and lateral upper and lower retinal fibres (fig 2 D). There was no evidence for intramyelinic oedema, which has been described in some animals exposed to vigabatrin. ${ }^{6}$ This would correlate with a recent report by Cohen et al, who found no evidence for 

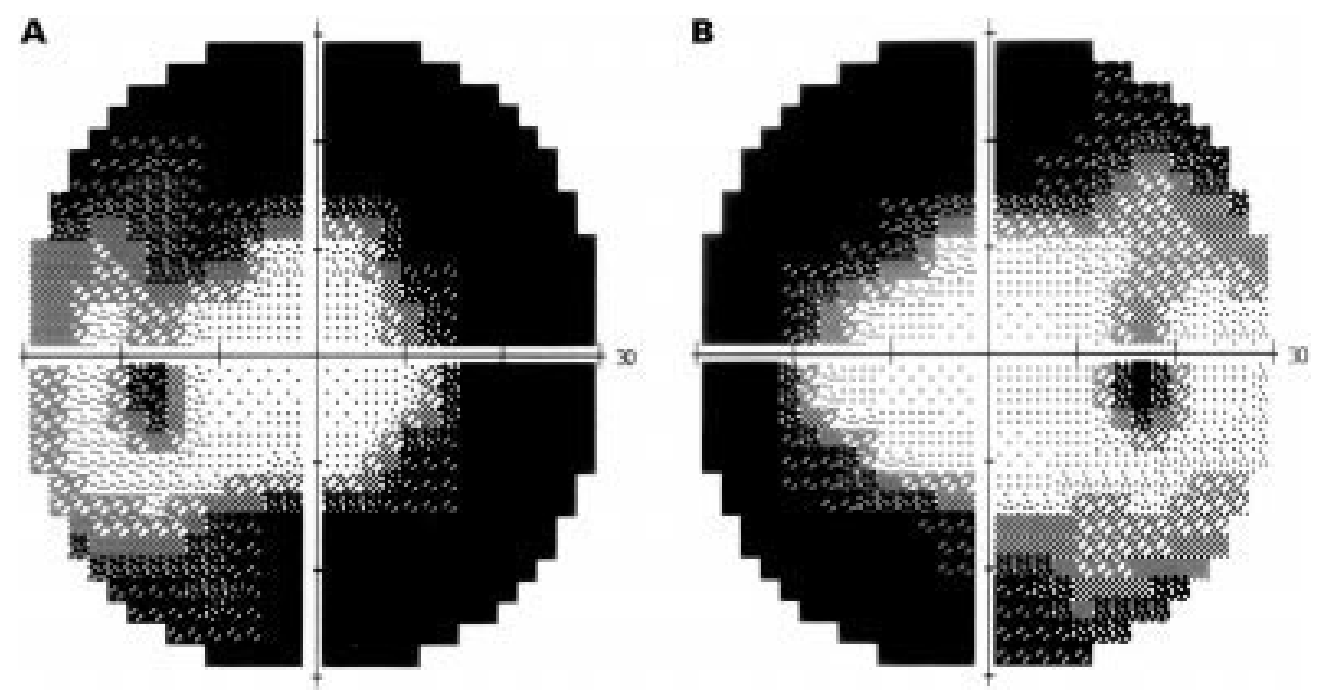

Figure 1 (A) Left eye and (B) right eye show bilateral visual field constriction with greater loss of the nasal visual fields. Automated visual fields 1 month before death. (Humphrey field analyser central 30-2 threshold tests.)

intramyelinic oedema in humans exposed to vigabatrin.

Since the first description of visual field defects several hypotheses have been postulated as to the anatomical basis of the visual field constriction. ${ }^{35}$ The visual field loss in this case, a bilateral concentric constriction is characteristic of the previously reported pattern
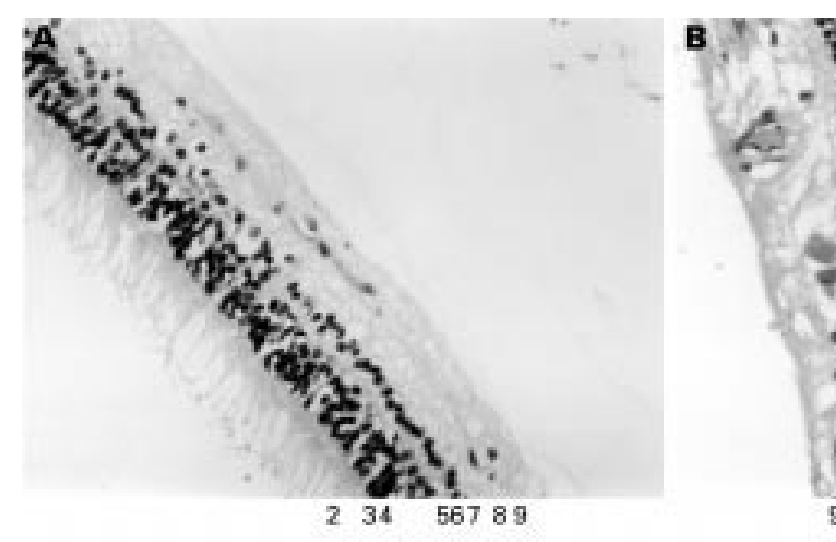

associated with vigabatrin. ${ }^{8}$ The peripheral retinal atrophy and relative preservation of the macular regions correlates well with the concentric visual field loss and relative preservation of central vision. The pattern of nerve fibre loss in the optic nerves, chiasm, and optic tracts is consistent with the loss of peripheral retinal ganglion cells and relative preservation
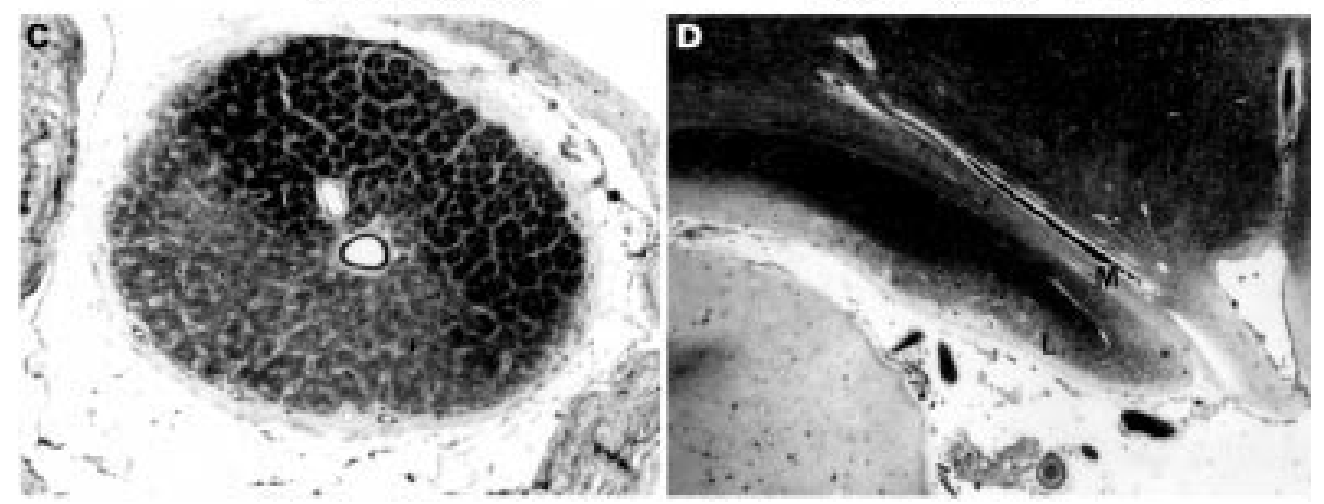

Figure 2 Temporal right retina (A) showing retinal atrophy with loss of ganglion cells (layer 8), partial loss of nuclei from inner nuclear layer 6 and outer nuclear layer 4 and atrophy of outer and inner plexiform (layers 5 and 7) and nerve fibre layers (9) compared with (B) normal control tissue (haematoxylin and eosin stained paraffin sections of formalin fixed tissue. Postmortem delay of 15 hours with consequent autolysis involving especially layer 2 of rods and cones $(A$ and $B$ originally $\times 250)$ ). $1=$ Pigment cell layer; $2=$ layer of rods and cones; $3=$ outer limiting membrane; $4=$ outer nuclear layer; $5=$ outer plexiform layer; $6=$ inner nuclear layer; $7=$ inner plexiform layer; $8=$ ganglion cell layer; $9=$ nerve fibre layer. $(C)$ Right optic nerve showing overall atrophy (half to one third normal) with relative preservation of the macular fibres (Masson trichrome stain originally $\times 24$ ). (D) Left optic tract showing loss of myelin staining in medial (upper retinal fibres) and lateral (lower retinal fibres) regions and relative preservation of the central macular fibres. $M=m e d i a l$ (upper retinal fibres); $L=$ lateral (lower retinal fibres) (Weil stain originally $\times 12$ ). 
of those in the macular regions. ${ }^{9}$ There was also loss of nuclei from the outer nuclear layer 4 (rods and cones) and the inner nuclear layer 6 but further cellular subtyping including bipolar and amacrine cells was not possible and we cannot be certain of the primary target(s) of injury. The degree of atrophy seen in the retina would suggest that the visual field loss would be irreversible.

Studies of the human retina show that some bipolar and amacrine cells are GABA positive. ${ }^{10}$ It has been speculated that GABA is cytotoxic to retinal cells, especially bipolar cells when in increased concentration. It is possible that gabapentin acts synergistically with vigabatrin to promote high retinal concentrations of GABA. Other GABAergic drugs have been implicated in the aetiology of constricted visual field defects, raising the possibility of a class effect. ${ }^{11}$ The toxicity of vigabatrin on these cells may not be related to increased GABA concentrations directly; glutamate, a metabolite of GABA, may be the mediator of cell damage.

Electroretinogram (ERG) studies of visual field loss associated with vigabatrin have disclosed an abnormality of the $b$ wave, which is generated from the inner retina (cone system). Oscillatory potential responses were also lost suggestive of amacrine cell dysfunction. ${ }^{12}{ }^{13}$ The pathological changes described in this case may explain the discrepancy in the ERG findings as some degree of atrophy of the cone system was seen. However the predominant loss seemed to be in the ganglion cell layer. Miller et al noted optic nerve atrophy in some patients and changes in the visual evoked potentials in other patients exposed to vigabatrin. ${ }^{13}$ This finding raises the possibility of a differential effect on areas of the retina, with some patients experiencing greater loss in the ganglion cell layer whereas in others, the damage occurs in other parts of the retina.

Concomitant use of sodium valproate has been implicated in potentiating the adverse effects of vigabatrin therapy on visual fields. ${ }^{14}$ However, this finding remains controversial. ${ }^{15}$ The patient reported had received long term sodium valproate therapy, which may have placed him at further risk of developing constricted visual fields. The dose of vigabatrin prescribed was in excess of the recommended maximum (4 g/day), which could also be a contributory factor. Review of the literature has not shown any reports of concentric visual field constriction as a complication of cyanotic heart disease. Cortical ischaemic events would not lead to atrophy of ganglion cells in the retina or of the optic nerves or optic tracts.

More detailed study of the effects of sustained doses of GABAergic agents on the retina may help elucidate the pathophysiological mechanisms of the visual field defect.

We are indebted to Drs W Cobain, R Adams, J Corbett, T Welch, A Weissenberger, and B Farage for providing some of the clinical details. We thank Drs L Bignold, M Scharpnel, and T Dodd for assistance with the postmortem.

1 Petroff OA, Rothman DL. Measuring human brain GABA in vivo: effects of GABA-transaminase inhibition with vigabatrin. Mol Neurobiol 1998;16:97-121.

2 Eke T, Talbot JF, Lawden MC. Severe persistent visual field constriction associated with vigabatrin. BMF 1997;314: $180-1$.

3 Kalviainen R, Nousiainen I, Mantyjarvi M, et al. Vigabatrin a gabaergic antiepileptic drug, causes concentric visual a gabaergic antiepileptic drug, causes
field defects. Neurology 1999;53:922-6.

4 Lawden MC, Eke T, Degg C, et al. Visual field defects associated with vigabatrin therapy. $\mathcal{F}$ Neurol Neurosurg Psychiaciated with vigabatrin

5 Harding GF. Severe persistent visual field constriction associated with vigabatrin. Four possible explanations exist [letter]. BMF 1997;314:1694.

6 Graham D. Neuropathology of vigabatrin. $\mathrm{Br} f \mathrm{Clin}$ Pharmacol 1989;27:43-5S.

7 Cohen JA, Fisher RS, Brigell MG, et al. The potential for vigabatrin-induced intramelinic edema in humans. Epilepsia $2000 ; 41: 148-57$.

8 Wild MJ, Martinez C, Reinshagen G, et al. Characteristics of a unique visual field defect attributed to vigabatrin. Epilepsia 1999;40:1784-94.

9 Sadun AA. Anatomy and physiology of the optic nerve. In: Miller NR, Newman NJ, eds. Walsh and Hoyt's clinical neuro-ophthalmology. 5th ed. Philadelphia: Williams and neuro-ophthalmology. 5th
Wilkins; 1997;1:57-85.

10 Van Haesendonck E, Missotten L. A subgroup of bipolar cells in the human retina is GABA-immunoreactive. Neurocells in the human retina is
sci Lett 1993;161:187-90.

11 Baulac M, Nordmann J-P, Lanoe Y. Severe visual-field constriction and side-effects of GABA-mimetic antiepileptic agents. Lancet 1998;352:546.

12 Krauss GL, Johnson MA, Miller NR. Vigabatrin associated retinal cone system dysfunction. Neurology 1998;50:61418.

13 Miller NR, Johnson MA, Paul SR, et al. Visual dysfunction in patients receiving vigabatrin: clinical and electrophysiological findings. Neurology 1999;53:2082-7.

14 Arndt CF, Derambure P, Defoort-Dhellemmes S, et al. Outer retinal dysfunction in patients treated with vigabatrin. Neurology 1999;52:1201-5.

15 Hirsch E. Outer retinal dysfunction in patients treated with vigabatrin. Neurology 2000;54:1396. 